\title{
Cloning and Expression of the Gene for Murine Granulocyte- Macrophage Colony-Stimulating Factor
}

\author{
N. M. Gough ${ }^{1}$, J. Gough ${ }^{1}$, D. Metcalf ${ }^{2}$, A. Kelso ${ }^{2}$, D. Grail ${ }^{1}$, N.A. Nicola ${ }^{2}$ \\ and A.R. Dunn ${ }^{1}$
}

\section{A. Introduction}

It has become apparent from studies in vitro that the survival, proliferation and differentiation of progenitor cells and functional activation of the various mature cell types of the haemopoietic system are controlled by a group of glycoprotein regulators, notably erythropoietin, $\mathrm{T}$ cell growth factor (IL2) and the colony-stimulating factors (CSFs) [1, 2]. Four CSFs with distinct biochemical and biological properties have been purified: $\mathrm{M}-\mathrm{CSF}$ is a selective proliferative stimulus for macrophages [3]; G-CSF for granulocytes [4]; GM-CSF for both granulocytes and macrophages [5]; while multi-CSF (also known as interleukin-3 [6], burst-promoting activity [7], $P$ cell-stimulating factor [8], mast cell growth factor [9] and haemopoietic cell growth factor [10]) stimulates the proliferation not only of neutrophilic granulocytes and macrophages, but also eosinophils, megakaryocytes, erythroid and mast cells. GM-CSF synthesized by mouse lung tissue is a glycoprotein of molecular weight 23000 [5] and is required continuously for the in vitro proliferation of progenitor cells of granulocytes and macrophages, controls the irreversible commitment of these progenitors

1 Melbourne Tumour Biology Branch, Ludwig Institute for Cancer Research, Post Office, Royal Melbourne Hospital, Melbourne, Vic., 3050 Australia

2 The Walter and Eliza Hall Institute for Medical Research, Post Office, Royal Melbourne Hospital, Melbourne, Vic., 3050 Australia to the formation of mature granulocytes and macrophages [11] and regulates the functional activity of the mature end cells. Although it has been possible to purify all four CSFs, detailed analysis of many aspects of the biology and biochemistry of these factors has been hampered by the limited quantities available. This problem can be largely circumvented by molecular cloning of the corresponding gene sequences and by using the cloned gene sequence to direct the synthesis of the corresponding factor. We have previously isolated cDNA clones containing partial copies of the GM-CSF mRNA from mouse lung [12]. In this paper we report the isolation of a cDNA clone which contains all of the information required to direct the synthesis of biologically active GM-CSF in simian COS cells [13].

\section{B. Results}

\section{Cloning of Murine GM-CSF cDNA Sequences}

We have recently isolated two cDNA clones complementary to the GM-CSF mRNA from the lungs of endotoxin-treated mice [12]. The structure of this mRNA is illustrated in Fig. 1. We have previously shown by Northern blot analysis that this mRNA is approximately 1200 nucleotides in length [12], of which 100-200 nucleotides are presumably contributed by the poly(A)tail. Nucleotide sequence analysis of the two cDNA clones (pGM37 and pGM38 in Fig. 1) complementary to 

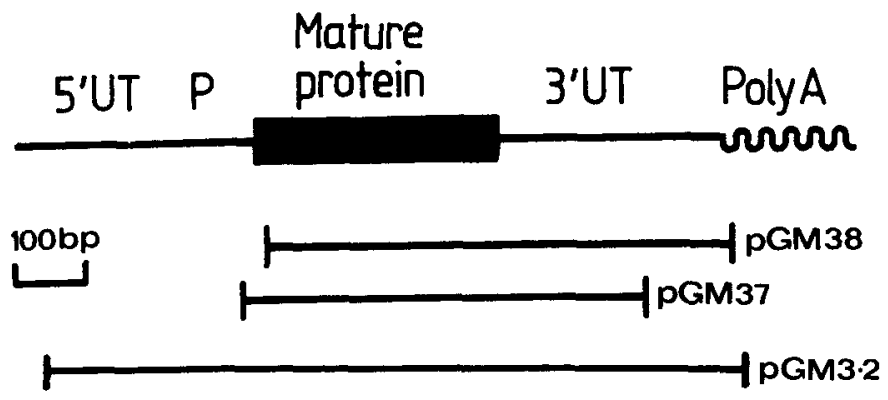

Fig. 1. Map of the murine GM-CSF mRNA. The region of the mRNA encoding the mature protein is shown as a thick line, the untranslated regions are designated by $U T$ and the putative precursor peptide by $P$. The regions contained within clones pGM37, pGM38 and pGM3.2 are indicated with bars

IleIleVal Thr ArgProTrpLysHis ValGluAlaIle LysGluAlaLeuAsnLeuLeu 20

AspAspMet Pro Val Thr LeuAsnGluGlu ValGlu Val Val SerAsnGluPheSer Phe 40

LysLysLeuThrCys ValGInThrArgLeuLysIlePheGluGlnGlyLeuArgGlyAsn 60

Phe Thr Lys LeuLysGly AlaLeuAsnMet Thr AlaSer Tyr TyrGln ThrTyrCys Pro 80

ProThr ProGluThrAspCysGluThrGlnVal Thr Thr Tyr AlaAsp Phe IleAspSer 100

LeuLys Thr Phe LeuThrAspIle ProPheGluCys Lys Lys ProSerGlnLys

118

Gly

Fig. 2. Predicted amino acid sequence of murine GM-CSF. The sequence presented is of the mature protein and is that predicted by nucleotide sequence analysis [12] of clones pGM37 and pGM38. Owing to a nucleotide sequence difference between the two clones, residue 116 could be either glycine or serine [12]

this mRNA indicated that the $3^{\prime}$ untranslated region of the mRNA is 319 nucleotides in length and the region encoding the mature protein is 354 nucleotides, leaving some 350 nucleotides for the putative $\mathrm{NH}_{2}$ terminal signal peptide and the $5^{\prime}$ untranslated region [12]. The amino acid sequence of GM-CSF deduced from the nucleotide sequence of the mRNA is given in Fig. 2, starting with the first amino acid of the mature protein [14]. The protein is predicted to be 118 amino acids in length, with a molecular weight of 13500 . The cDNA sequence in clone pGM37 extends about 20 nucleotides $5^{\prime}$ to the region encoding the mature protein, into the region encoding the signal peptide, but does not extend to the translational initiation codon.

As a prelude to the direct expression of the cloned GM-CSF gene sequence in cell culture, we needed to isolate a cDNA clone containing the entire coding region of the GM-CSF mRNA, including the translation- al initiation codon. In order to isolate more GM-CSF cDNA clones we have made use of a cloned T lymphocyte line, LB3 [15], in which the synthesis of high levels of GMCSF mRNA is inducible by concanavalin A (see Fig. 2 in reference [12]). We estimate the abundance of GM-CSF mRNA in conA-stimulated LB3 RNA to be at least two orders of magnitude greater than in lung RNA. We therefore constructed a library of cDNA clones complementary to con-Astimulated LB3 RNA, and screened this library for GM-CSF clones by colony hybridization using a fragment of DNA from $\mathrm{pGM} 38$ as a probe. Of 24 GM-CSF cDNA clones purified and examined, one (pGM3.2) appears to contain a substantial, if not complete, copy of the GM-CSF mRNA. The region of GM-CSF mRNA contained in this clone, determined by mapping the location of various restriction endonuclease sites, is illustrated in Fig. 1.

\section{Direct Expression of GM-CSF in COS Cells}

In order to be able to express eukaryotic cDNA sequences in cell culture, we have constructed a vector ( $\mathrm{pJL}$ ) which utilizes the late promoter of the simian virus SV40 to transcribe inserted DNA sequences 
(Fig. 3). The vector contains the $\beta$-lactamase gene and origin of DNA replication from the bacterial plasmid pAT153 [16], the SV40 origin of DNA replication and T antigen coding sequences [17] and a "multicloning site" adjacent to the SV40 late promoter. This multicloning site contains cleavage sites for several restriction endonucleases suitable for insertion of foreign DNA sequences: Eco RI, Bam HI, SacI, $X b a I$, SalI and SmaI. When introduced into cultured simian cells, such as CV1 or $\operatorname{COS}$ [13], this vector is able to replicate and to transcribe any DNA sequence inserted at the multicloning site. Provided that translational start and stop codons are included, the inserted sequence will be translated.

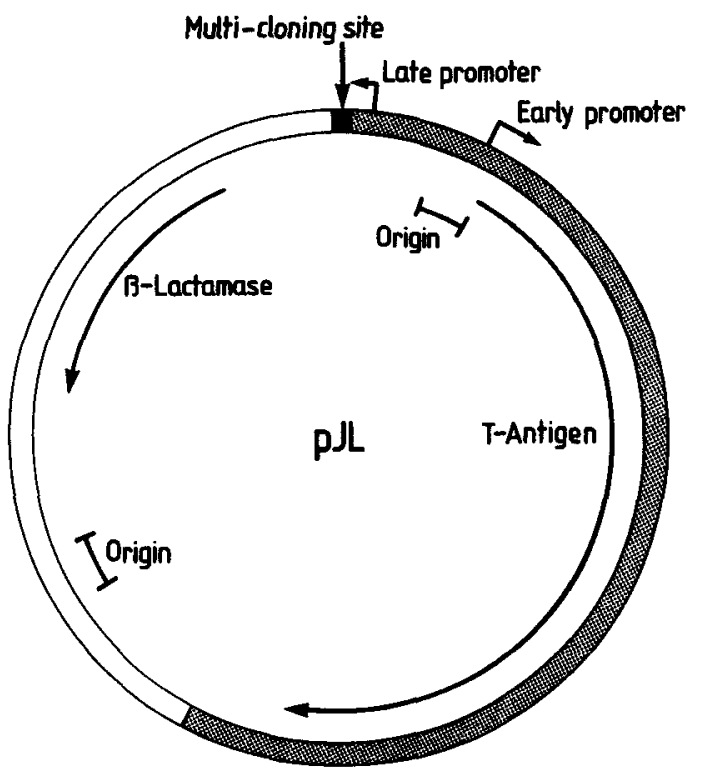

Fig. 3. Map of the expression vector $p J L$. The region derived from pAT153 [16] is indicated by an open segment, that from SV40 [17] by stippling and the multicloning site is filled in
The cDNA sequence of clone pGM3.2 has been installed in the multicloning site of $\mathrm{pJL}$ with the GM-CSF coding region in the same orientation as transcription from the late promoter. This recombinant was introduced into COS cells essentially as described by Dana and Sompayrac [18] and the culture medium assayed for GM-CSF activity $48 \mathrm{~h}$ after transfection. As negative controls, COS cells were also transfected with pJL DNA alone or with two different recombinant plasmids containing incomplete copies of the GM-CSF mRNA; COS cells which received no DNA were also assayed for GM-CSF activity. The various conditioned media were assayed for GM-CSF activity using both the FD cell line, which is absolutely dependent upon the presence of either GM-CSF or multiCSF for growth (A. Hapel, personal communications) and the 32D CL3 cell line [19], which is responsive only to multi-CSF. As shown in Fig. 4, the medium for COS cells transfected with pGM3.2 DNA was able to support the growth of FD cells whereas media from all of the negative controls were completely inactive. As expected, the medium from pGM3.2-transfected COS cells was inactive on 32D CL3 cells (not shown), indicating that the active factor was GM-CSF rather than multi-CSF. The medium from pGM3.2-transfected COS cells also stimulated the formation of morphologically identifiable granulocyte and macrophage colonies in agar cultures containing bone marrow cells (Table 1) [5], the ratio of the three colony types being characteristic of GM-CSF at these concentrations [20]. The full range of biological ac-
Table 1. Colony formation by mouse bone marrow cells stimulated with medium from pGM3.2-transfected COS cells ${ }^{\mathrm{B}}$

\begin{tabular}{llll}
\hline $\begin{array}{l}\text { Total number } \\
\text { of colonies }\end{array}$ & \multicolumn{2}{l}{ Colony type (\%) } \\
\cline { 2 - 4 } & Granulocyte & $\begin{array}{l}\text { Mixed granulo- } \\
\text { cyte macrophage }\end{array}$ & $\begin{array}{l}\text { Macro- } \\
\text { phage }\end{array}$ \\
\hline 33 & 15 & 19 & 66 \\
23 & 27 & 27 & 46 \\
24 & 17 & 17 & 66
\end{tabular}

a Medium from three separate cultures of COS cells transfected with pGM3.2 DNA were assayed in agar cultures containing 75000 C57BL/ 6 bone marrow cells [5] 


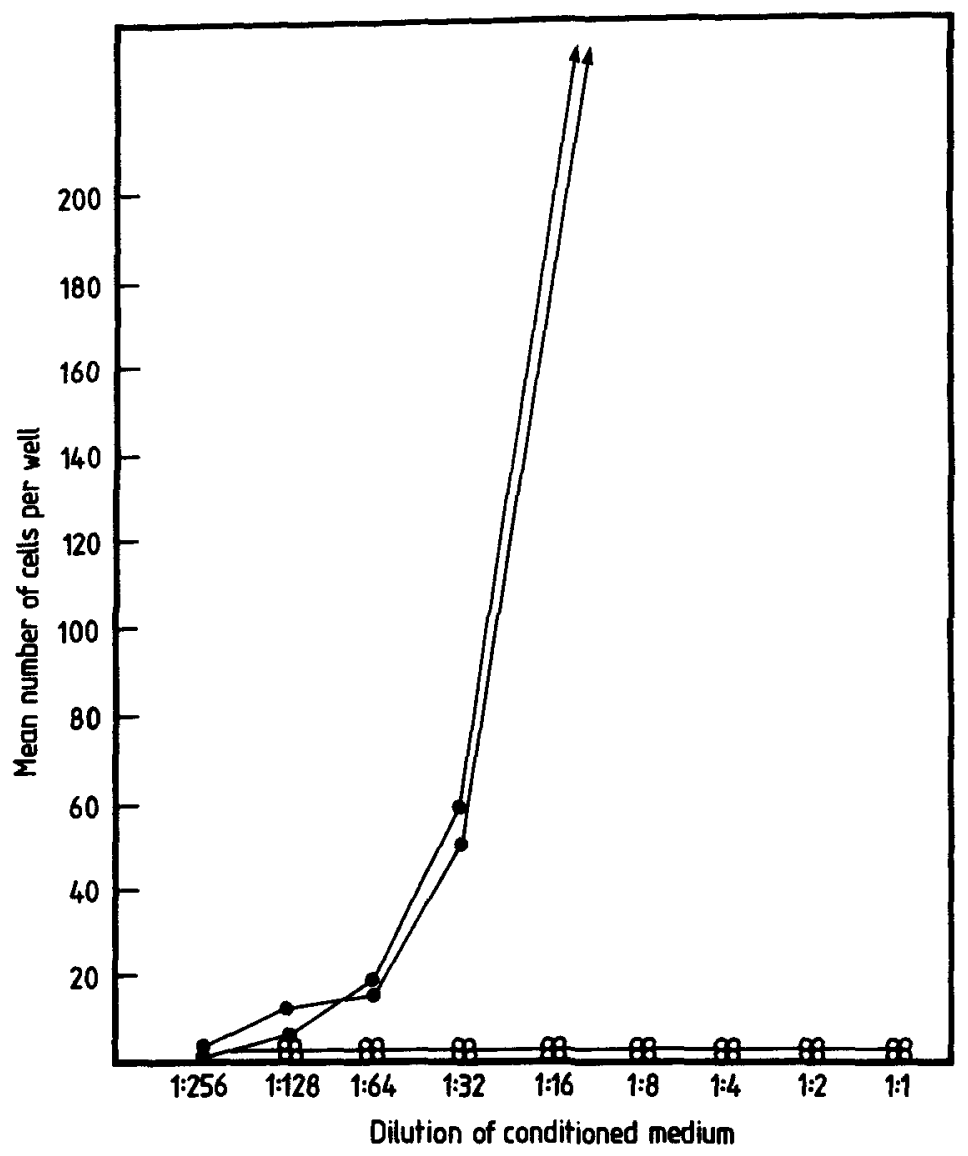

Fig. 4. Stimulation of cellular proliferation in suspension cultures of FD cells by medium from DNA-transfected COS cells. Clone pGM3.2 DNA is indicated with full circles and vector DNA ( $\mathrm{pJL}$ ), two clones containing partial copies of the GM CSF mRNA and COS cells which received no DNA are indicated with open circles; $5-\mu$ l volumes of conditioned medium were assayed in serial dilutions in 15- $\mu$ cultures containing 300 FD cells. Each point is the mean cell count from duplicate cultures after 2 days of incubation tivities of the factor specified by this cloned gene is currently being assessed.

\section{Conclusion}

The molecular cloning of genes encoding the various haemopoietic growth regulators should allow the resolution of many outstanding questions and also bring to light hitherto unappreciated problems. By nucleotide sequence analysis of cloned gene sequences, the complete amino acid sequences of murine GM-CSF [12] and multi-CSF [21, 22] have been deduced - a goal that was essentially unattainable by conventional biochemical approaches. Comparison of these two sequences has now raised further intriguing issues. As we have previously discussed [12], neither the primary amino acid sequences nor the predicted secondary structures of these two factors show any significant homology, despite the similar activities that they display in stimulating the growth of granulocyte and macrophage colonies from committed progenitor cells. It should now be possible to study in more detail the interaction between these two factors and their receptors, since we can now produce both GM-CSF (this paper) and multi-CSF (N.M. Gough, unpublished work) in a clonally pure form upon introduction of the cloned gene sequences into COS cells. Moreover, by in vitro mutagenesis and expression of the mutated gene sequences it should be possible to dissect the active site (or sites) of the molecules and to ask whether their various activities are determined by the same or different active sites.

Acknowledgments. The work at the Walter and Eliza Hall Institute was supported by grants from the Carden Fellowship Fund of the Anti-Cancer Council of Victoria, the NH and MRC (Canberra) and the NIH (Bethesda) grant numbers CA 22556 and CA 25972.

\section{References}

1. Metcalf D, Moore MAS (1971) Haemopoietic cells. North Holland, Amsterdam

2. Metcalf D (1981) In: Baserga R (ed) Tissue growth factors. Springer, New York, pp 343 $-384$ 
3. Stanley ER, Heard PM (1977) J Biol Chem 252:4305-4312

4. Nicola NA, Metcalf D, Matsumoto M, Johnson GR (1983) J Biol Chem 258:9017-9021

5. Burgess AW, Camakaris J, Metcalf D (1977) J Biol Chem 252: 1998-2003

6. Ihle $\mathrm{JN}$ et al. (1982) J Immunol 129: 2431-2436

7. Iscove NN, Roitsch CA, Williams N, Guilbert LJ (1982) J Cell Physiol [Suppl] 1:65-78

8. Clark-Lewis I, Schrader JW (1981) J Immunol 127: 1941-1947

9. Yung, Y-P, Eger R, Tertlan G, Moore MAS (1981) J Immunol 127:794-799

10. Bazill GW, Haynes M, Garland J, Dexter TM (1983) Biochem J 210:747-759

11. Metcalf D, Burgess AW (1982) J Cell Physiol 111:275-283

12. Gluzman Y (1981) Cell 23: 175-182

13. Gough NM et al. (1984) Nature 309:763-767

14. Sparrow L et al. (1985) Proc Natl Acad Sci USA 82:292-296
15. Kelso A, MacDonald HR, Smith KA, Cerottini J-C, Brunner KT (1984) J Immunol 132: 2932-2938

16. Twigg AJ, Sherratt D (1980) Nature 283: 216-218

17. Tooze J (1980) Molecular biology of tumour viruses, part 2: DNA tumour viruses. Cold Spring Harbor Laboratory

18. Danna KJ, Sompayrac LM (1982) J Virol Methods 5:335-341

19. Greenberger JS et al. (1982) In: Baum SJ, Ledney GD, Thierfelder S (eds) Experimental haematology today 1982. Karger, Basel, pp 195-209

20. Burgess AW, Metcalf D (1977) In: Baum SJ, Ledney GD (eds) Experimental haematology today 1977. Springer, New York, pp 135-146

21. Fung MC et al. (1984) Nature 307:233-237

22. Yakota $T$ et al. (1984) Proc Natl Acad Sci USA 81: 1070-1074 